Parasitology Open

cambridge.org/pao

\section{Corrigendum}

Cite this article: Thomson $S$, Innes EA, Jonsson NN, Katzer F (2019). A multiplex PCR test to identify four common cattle-adapted Cryptosporidium species - CORRIGENDUM. Parasitology Open 5, e1, 1. https://doi.org/ 10.1017/pao.2018.16

\title{
A multiplex PCR test to identify four common cattle-adapted Cryptosporidium species - CORRIGENDUM
}

Sarah Thomson, Elisabeth A. Innes, Nicholas N. Jonsson and Frank Katzer

doi: 10.1017/pao.2016.2, published by Cambridge University Press, 22 April 2016

The authors apologise for errors in some of the primer sequences contained in Table 1 of the above paper. The corrected Table appears below:

Table 1. Primer sequences, size of amplicon and species detected with each primer pair

\begin{tabular}{|c|c|c|c|}
\hline Primer Pair & Sequence $5^{\prime}-3^{\prime}$ & $\begin{array}{l}\text { Fragment } \\
\text { Size (bp) }\end{array}$ & $\begin{array}{c}\text { Species } \\
\text { Detected }\end{array}$ \\
\hline AL1687 (EF) & TTCTAGAGCTAATACATGCG & \multirow[t]{2}{*}{1370} & Genus Specific \\
\hline AL1691 (ER) & CCСАTTTCTTCGAAACAGGA & & External \\
\hline AL1598 (IF) & GG*AAGGGTTGTATTTATTAGATAAAG & \multirow[t]{2}{*}{840} & Genus Specific \\
\hline AL3032 (IR) & AAGGAGTAAGGAACAACCTCCA & & Internal \\
\hline $\mathrm{CaF}$ & GCAAATTACCCAATCCTGAC & \multirow[t]{2}{*}{625} & \multirow[t]{2}{*}{ C. andersoni } \\
\hline AL3032 (IR) & AAGGAGTAAGGAACAACCTCCA & & \\
\hline CrF & 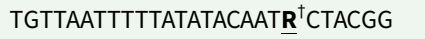 & \multirow[t]{2}{*}{415} & \multirow[t]{2}{*}{ C. ryanae } \\
\hline AL3032 (IR) & AAGGAGTAAGGAACAACCTCCA & & \\
\hline CphF & AGAGTGCTTAAAGCAGGCATA & \multirow[t]{2}{*}{305} & \multirow[t]{2}{*}{ C. parvum } \\
\hline AL3032 (IR) & AAGGAGTAAGGAACAACCTCCA & & \\
\hline CbF & CTTCTTATTG ${ }^{\ddagger} \mathrm{G}^{\ddagger}$ TTCTAGAATAAAA ATG & \multirow[t]{2}{*}{241} & \multirow[t]{2}{*}{ C. bovis } \\
\hline AL3032 (IR) & AAGGAGTAAGGAACAACCTCCA & & \\
\hline
\end{tabular}

${ }^{*}$ This base was omitted in the originally published Table

tThe degenerate base in the C. ryanae primer is shown in bold and underlined

期ese bases were mistakenly written as $\mathrm{C}$ in the originally published Table

\section{Reference}

Thomson S., Innes E. A., Jonsson N. N. and Katzer F. (2016). A multiplex PCR test to identify four common cattle-adapted Cryptosporidium species. Parasitology Open 2, e5. Published by Cambridge University Press, 22 April 2016. doi: 10.1017/pao.2016.2. 